innovative writings of my brother Murray Cox (forensic psychotherapist and Shakespeare scholar), whose edited book Remorse and Reparation was published posthumously (Cox, 1999). It included a discussion of Shakespearean language about guilt and remorse, an analysis of Kierkegaard's psychological and theological thinking, and chapters on novel aspects of forensic psychiatry.

The three thematic papers that follow shine a ray of hope on what is otherwise a gloomy political landscape at present. This writer recalls celebrating Victory in Europe (VE) day in 1945 - but, at the time, none of us knew of the ethnic cleansing of thousands of German-speaking civilians that would occur in Eastern Europe as a consequence of the post-war agreements between the Western powers and Stalin (de Zayas, 1977: pp. xxv, 54).

These papers and these people will remind the reader that psychiatry and medicine as a whole is an interpersonal discipline that is sans frontières. Benjamin Britten used the poetry of Wilfred Owen for his War Requiem (1962), including Owen's 'Strange meeting', written in 1918, which features the line:

I am the enemy you killed, my friend.

The music does not shirk the dark shadows and can enlighten us, as well as promote reconciliation.

\section{References}

Clein, L. (2013) Obiturary: Dr Nathaniel Minton MA, DPM, FRCPsych. The Psychiatrist, 37, 248-248.

Cox, M. N. (1999) Remorse and Reparation. Jessica Kingsley.

de Zayas, A. M. (1977) Nemesis at Potsdam: The Anglo-Americans and the Expulsion of the Germans. Routledge \& Kegan Paul.

Watts, G. (2015) Alex Poteliakhoff: campaigner for a less violent world. Lancet, 385, 2143

\section{THEMATIC PAPER}

\title{
Committing to reconciling our differences: development of the Royal Australian and New Zealand College of Psychiatrists' Reconciliation Action Plan
}

\author{
Jason B. L. Lee
}

Clinical Director, Rural, Remote and Indigenous Mental Health Services, Mental Health Service Group, The Townsville Hospital, Australia, email drkamikaze@ hotmail.com

\section{Declaration of interest: the} author was chair of the Roya Australian and New Zealand College of Psychiatrists' Aboriginal and Torres Strait Islander Mental Health Committee at the time of the development of the Reconciliation Action Plan and at the time of the writing of this article.
Aboriginal and Torres Strait Islander Australians continue to experience disproportionately poor physical and mental health, and inequity of opportunity. Australia's Reconciliation Action Plan programme provides a framework and support for organisations to demonstrate leadership through public commitment to actions. The Royal Australian and New Zealand College of Psychiatrists developed its own Reconciliation Action Plan through a consultative process, and hopes to lead and promote reconciliation as a peak medical body.

\section{Background}

Aboriginal and Torres Strait Islander people are the Indigenous populations of Australia. Archaeological evidence suggests that human colonisation of the continent dates as far back as 68000 years (Thorne et al, 1999). Indigenous Australians were hunter-gatherer societies, deeply spiritual, whose wisdom and cultural knowledge were transmitted through stories and rituals involving songs, dance and art. Prior to colonial settlement in 1788 , the population, an estimated 750000 people, spoke several hundred different languages (Australian Bureau of Statistics, 2008).

The impact of European settlement was rapid and devastating. War, disease and dispossession changed living conditions and caused a rapid decline in population, to a low of 93000 in 1900 (Australian Bureau of Statistics, 2002). Longitudinally, the sequelae and continuing impact of historical and trans-generational trauma have resulted in many Indigenous youths engaging in dysfunctional behaviours, from crime and violent behaviours through to substance misuse and self-harm (Atkinson, 2002). This maelstrom of cumulative trauma contextualises the sub-optimal social and emotional well-being, and indeed the mental ill-health, experienced by many Aboriginal and Torres Strait Islander people.

Social, economic and environmental factors have a pivotal role in cumulatively increasing the lifetime risk of an individual experiencing physical and mental ill-health. Indigenous Australians experience higher rates of incarceration, unemployment, household overcrowding and domestic violence. Their life expectancy is 10.6 and 9.5 years less than male and female nonIndigenous Australians (Australian Government, 2015). Addressing these disadvantages requires engagement from individuals, communities and all levels of government, with multi-sectorial and multi-systemic interventions. Australia's journey of reconciliation with its Indigenous people has been slow to gain momentum, with the most significant milestones arguably being the 1967 referendum (to include Indigenous Australians in the census and 
allow the Commonwealth to make laws for them), the 1992 Mabo native title decision (the High Court found that terra nullius - the notion that the land belonged to no one - should not have applied to Australia), and the 2008 'stolen generations' national apology (for past mistreatment, particularly children forcibly removed from families).

Despite significant recent commitment and investment in social policies and projects, progress in ensuring Indigenous Australians have equal opportunity to participate in society has been limited. The 2015 Closing the Gap report showed encouraging signs in Indigenous child mortality and child and youth participation in education, but little improvement in life expectancy, employment and literacy (Australian Government, 2015). The sixth Overcoming Indigenous Disadvantage report, comparing 2004-05 and 2011-12 rates, found no significant change in alcohol and drug misuse and harm, while the proportion of Aboriginal and Torres Strait Islander adults reporting high levels of psychological distress increased from $27 \%$ to $30 \%$, and hospitalisations for self-harm by $48 \%$ (Australian Government, 2014).

While measurable outcomes serve as focal targets, cultural identity and recognition by and respect from others are no less important in the efforts to help Aboriginal and Torres Strait Islander people to their rightful place in Australian history and contemporary society. Cultural factors, despite being severely damaged by European colonisation, helped Aboriginal and Torres Strait Islander people survive generations of trauma and disadvantage, and continue to protect them from racism and marginalisation (Zubrick et al, 2014). One current such activity is the push for recognition of Aboriginal and Torres Strait Islander people in the Australian Constitution.

Reconciliation then is about improving the relationship between Aboriginal and Torres Strait Islander people and the rest of the Australian population, through addressing inequity of opportunity, enhancing recognition of cultural identity and building respect.

In the words of Pitjantjatjara elder Nganyinytja, 'Reconciliation means bringing two cultures together: maru munu piranpa tjun-gurin-ganyi, Black and White coming together' (Nganyinytja, 2010).

\section{Reconciliation Australia's Reconciliation Action Plan (RAP) programme}

Reconciliation Australia is an independent national not-for-profit organisation. It launched its RAP programme in 2006 to support organisations to develop business plans that target change within their spheres of influence to address social determinants of health and contribute to the national 'Closing the Gap' targets of Indigenous life expectancy, employment and high-school completion rates. The programme grew from eight organisations in 2006 to more than 600 in 2014 (Reconciliation Australia, 2014).

Reconciliation action plans promote commitments to actions under the three pillars of building relationships, showing respect and improving opportunities. Four types of RAP are available, depending on the organisation's experience in reconciliation, preference for engaging innovative or stretch targets, and track record of proven results.

In 2012, Reconciliation Australia demonstrated the effectiveness of the programme by reporting on several key findings: $45 \%$ of RAP employees agree that Aboriginal and Torres Strait Islander peoples hold a special place as the First Australians, compared with $21 \%$ of the general population; $77 \%$ of RAP employees are proud of Aboriginal and Torres Strait Islander cultures, compared with $51 \%$ of the general population; and $86 \%$ of RAP employees have taken action in support of reconciliation, compared with $50 \%$ of the general population (Reconciliation Australia, 2012). Furthermore, as of September 2013, RAP organisations employed 25755 Aboriginal and Torres Strait Islander peoples and purchased A $\$ 81$ million worth of goods and services from accredited Aboriginal and Torres Strait Islander organisations.

Organisations engaged in the RAP programme have ranged from private companies to small businesses, government agencies to local councils, and peak bodies to schools and universities, and have included peak medical bodies, including the Royal Australian and New Zealand College of Psychiatrists (RANZCP; see http://www.ranzcp. org/About-us/About-the-College/ReconciliationAction-Plan.aspx).

\section{Development of the RANZCP RAP}

One of the core values of the RANZCP is improved health outcomes and access to mental health services for Indigenous populations. It has therefore proactively developed internal mechanisms and external opportunities for meaningful consultation and collaborative partnerships with Indigenous stakeholders.

In 1997, the RANZCP established the Aboriginal and Torres Strait Islander Mental Health Committee (ATSIMHC) in Australia and the Te Kaunihera mo nga Kaupapa Hauora Maori Committee in New Zealand. Each committee aims to work with respective Indigenous peoples and organisations: to promote the mental health of their communities; to reduce the impact of mental disorders on individuals, families and the community; to ensure optimal and complementary recognition and application of the expertise of people and organisations involved in mental healthcare delivery to the communities; and to assure the rights of Indigenous peoples with mental disorders.

The ATSIMHC is composed of Aboriginal and Torres Strait Islander community members and psychiatrists working in Indigenous mental health. It enables the RANZCP and the mainstream of mental health providers to hear Aboriginal and Torres Strait Islander concerns in the areas of social and emotional well-being and mental health. Its roles within and on behalf of the RANZCP 
include: advocating on relevant issues at a national level; advising the RANZCP; supporting the establishment of collaborative relationships; advocating for and supporting Aboriginal and Torres Strait Islander mental health workers, doctors and medical students; and promoting public understanding.

Aside from the establishment of the ATSIMHC, the RANZCP has developed and maintained position statements on Aboriginal and Torres Strait Islander mental health workers, and the recognition of Indigenous people in the Australian Constitution, and 'stolen generations'; it has also produced an ethical guideline on Aboriginal and Torres Strait Islander mental health.

The RANZCP, led by its board, embraced the development of a RAP as an opportunity to contribute to and support the reconciliation process. The RAP was developed in consultation with the ATSIMHC, with targeted input and feedback sought from its Aboriginal and Torres Strait Islander membership. All RANZCP members were invited to contribute. Key stakeholder groups were consulted, including the Australian Indigenous Doctors Association and Reconciliation Australia. The RAP was launched at the RANZCP annual congress in May 2014, in the presence of Dr Tom Calma, co-chair of Reconciliation Australia.

The key to the RANZCP's successful development of a comprehensive and meaningful RAP is its long-standing interest in Indigenous health. The ATSIMHC, with its expertise and established relationships, provided appropriate advice and leadership. The actions committed to in the RAP represented work that was already underway, as well as aspirational goals, both practical and, as importantly, symbolic (Subašic \& Reynolds, 2009). An action under 'Respect' for supporting Fellows and trainees to enhance their cultural competency has recently been completed with the development of a series of e-learning modules on Indigenous mental health. An approach to an action under 'Relationships' to develop new partnerships and engage local communities has been to hold the ATSIMHC's meetings at different Aboriginal or Torres Strait Islander health services across Australia. Aspirational goals include an action under 'Opportunities' to support the recruitment and retention of Aboriginal and Torres Strait Islander psychiatrists and trainees, for which affirmative action is being considered. Moving forwards, a RAP steering group is being formed to oversee the RANZCP's progress towards its RAP goals. Significantly, the steering group will include two ATSIMHC community members, enabling culturally appropriate input at every point of the RAP process.

\section{Conclusion}

Aboriginal and Torres Strait Islander Australians have suffered tremendous losses as a legacy of colonial settlement. Reconciliation cannot change the past, but can begin to heal those wounds and provide a vehicle for correcting the inequities that persist and, in some instances, continue to worsen.
Reconciliation Australia's RAP programme provides a framework for organisations to contribute to meaningful change, and join the growing body of leadership in Australia to promote reconciliation. The RANZCP has developed its RAP through a multi-tiered consultation process, with Aboriginal and Torres Strait Islander involvement at every level. The challenge ahead will be to transform words into actions, and to celebrate and build on those successes as we continue on this journey of reconciliation.

\section{References}

Atkinson, J. (2002) Trauma Trails Recreating Song Lines: The Transgenerational Effects of Trauma in Indigenous Australia. Spinifex Press.

Australian Bureau of Statistics (2002) Year Book Australia, 2002. Available at http://www.abs.gov.au/ausstats/abs@.nsf/94713ad445 ff1425ca25682000192af2/bfc28642d31c215cca256b350010b3f 4!OpenDocument (accessed 20 December 2014).

Australian Bureau of Statistics (2008) Year Book Australia, 2008. Available at http://www.abs.gov.au/ausstats/abs@.nsf/0/68AE74 ED632E17A6CA2573D200110075?opendocument (accessed 20 December 2014).

Australian Government (2014) Overcoming Indigenous Disadvantage: Key Indicators 2014. Productivity Commission. Available at http://www.pc.gov.au/research/recurring/overcomingindigenous-disadvantage/key-indicators-2014 (accessed 5 January 2015).

Australian Government (2015) Closing the Gap: Prime Minister's Report 2015. Department of the Prime Minister and Cabinet. Available at http://www.dpmc.gov.au/sites/default/files/ publications/Closing_the_Gap_2015_Report_0.pdf (accessed 1 March 2015).

Nganyinytja (2010) Quoted on the Australian Inspiration website, http://www.australianinspiration.com.au/Quotes/Authors/N/ Nganyinytja.aspx (accessed 10 January 2015).

Reconciliation Australia (2012) Reconciliation Action Plan: Impact Measurement Report 2012. Available at http://www.reconciliation. org.au/raphub/wp-content/uploads/2013/03/2012-RAP-ImpactMeasurement-report.pdf (accessed 20 November 2014).

Reconciliation Australia (2014) Who has a RAP? On the 'About' page of the Reconciliation Australia website, http://www. reconciliation.org.au/raphub/about (accessed 20 November 2014).

Subašic, E. \& Reynolds, K. (2009) Beyond 'practical' reconciliation: intergroup inequality and the meaning of non-Indigenous identity. Political Psychology, 30, 243-267.

Thorne, A., Grün, R., Mortimer, G., et al (1999) Australia's oldest human remains: age of the Lake Mungo 3 skeleton. Journal of Human Evolution, 36, 591-612.

Zubrick, S., Shepherd, S., Dudgeon, P., et al (2014) Social determinants of social and emotional wellbeing. In Working Together: Aboriginal and Torres Strait Islander Mental Health and Wellbeing Principles and Practice (eds P. Dudgeon, H. Milroy \& R. Walker), pp. 93-112. Commonwealth of Australia.

\section{BJPsych International on Twitter} @ BJPsychInt

\section{BJPsychInternational retweeted} SANE @CharitySANE May 27

Good to hear announcement in \#QueensSpeech to ban the use of police cells for emergency detention of mentally ill people under the MHA. 